\title{
Determinants of gait speed in patients with heart failure with reduced ejection fraction
}

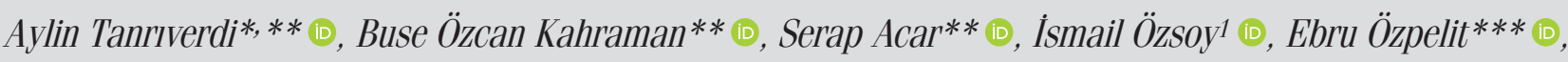 \\ Bihter Şentürk*** (1D, Bahri Akdeniz*** (1), Sema Savcl** (1) \\ Departments of *Institute of Health Sciences, and **School of Physical Therapy and Rehabilitation, \\ ***Cardiology, Faculty of Medicine, Dokuz Eylül University; İmir-Turkey \\ ${ }^{1}$ Department of Physiotherapy and Rehabilitation, Faculty of Health Sciences, Selçuk University; Konya-Turkey
}

\section{ABSTRACT}

Objective: Given the prognostic significance of gait speed, there is insufficient evidence about possible functional determinants of gait speed in patients with heart failure with reduced ejection fraction (HFrEF). Therefore, the objective of this study was to investigate the functional determinants of gait speed in patients with HFrEF.

Methods: Fifty-nine patients with HFrEF participated in this cross-sectional study. Demographic and clinical characteristics were recorded. The gait speed was determined with a 4-meter walking test. Dyspnea perception was assessed with the modified medical research council (mMRC) scale. Functional capacity was evaluated with a 6-minute walk test (6MWT). The five times sit-to-stand (5-STS) test and the Berg Balance Scale (BBS) were used to measure functional mobility and balance. Physical activity was evaluated with the International Physical Activity Questionnaire (IPAQ) Short-Form.

Results: Gait speed was correlated with age $(r=-0.368, p=0.004)$, NYHA functional class $(r=-0.438, p=0.001)$, mMRC score ( $r=-0.422, p=0.001)$, $6 \mathrm{MWT}(r=0.650, p<0.001)$, 5STS $(r=-0.506, p<0.001)$, BBS $(r=0.586, p<0.001)$, IPAO $(r=0.305, p=0.019)$ and IPAQ-Sitting time $(r=-0.327, p=0.011)$. 0n multiple linear regression analysis, the 6MWT distance and BBS were independent determinants of the usual gait speed in patients with HFrEF, accounting for $44.4 \%$ of the variance.

Conclusion: This study indicates that functional capacity and balance are independent functional determinants of gait speed in patients with HFrEF.

Keywords: balance, functional capacity, gait speed, heart failure, physical activity

Cite this article as: Tanrıverdi A, Özcan Kahraman B, Acar S, Özsoy I, Özpelit E, Şentürk B, et al. Determinants of gait speed in patients with heart failure with reduced ejection fraction. Anatol J Cardiol 2021; 25: 617-22.

\section{Introduction}

Heart failure (HF) is a major health problem showing an upward trend and affecting approximately 26 million people worldwide (1). In addition to central factors such as decreased cardiac output and oxygen delivery, peripheral factors such as decreased leg blood flow, vascular permeability, and muscle oxygen diffusion capacity lead to exercise intolerance in patients with HF (2). Exercise intolerance is associated with decreased quality of life and a poor prognosis (3). Indeed, a distance of fewer than $300 \mathrm{~m}$ covered in the 6 -minute walk test (6MWT) showing functional capacity is a prognostic marker for mortality in mild to moderate $\mathrm{HF}(4)$.
In the literature, it has been stated that gait speed, the value of which increases day by day, should also be considered as a functional "sixth vital sign" (5). In elderly people with cardiovascular disease (CVD), gait speed has been shown to have a similar prognostic capacity as the 6MWT distance (6). In addition, gait speed is significantly associated with mortality and hospitalization in patients over 70 years of age with HF across a wide range of ejection fraction (EF) (7). Moreover, each 0.1 $\mathrm{m} / \mathrm{s}$ increase in gait speed is associated with a $17 \%$ reduced risk of all-cause mortality and a $9 \%$ decreased risk of readmission in older patients with acute HF (8).

Information about functional mobility and balance performance is important in determining the level of function, changes

Address for Correspondence: MSc, PT Aylin Tanrıverdi, Dokuz Eylül Üniversitesi, Sağlık Bilimleri Enstitüsü, Fizik Tedavi ve Rehabilitasyon Yüksekokulu, İzmir-Türkiye

Phone: +90 5352359989 E-mail: tanrverdiaylin@gmail.com

Accepted Date: 22.03.2021 Available Online Date: 03.08.2021

(C) Copyright 2021 by Turkish Society of Cardiology - Available online at www.anatoljcardiol.com DOI:10.5152/AnatolJCardiol.2021.17735 


\section{HIGHLIGHTS}

- There is a lack of evidence about functional determinants of gait speed in patients with heart failure with reduced ejection fraction (HFrEF).

- Functional capacity and balance are independent functional determinants of gait speed in patients with HFrEF.

- Gait speed has the ability to predict poor exercise capacity in patients with HFrEF, making it an informative tool for patients with HFrEF.

over time, and health outcomes in the elderly people and the patient population living in the community (9-11). Increased gait speed was found to be one of the independent variables of functional capacity during 6MWT in patients with HF (12). However, given the prognostic significance as well as an easy, reliable, precise and rapid measurement of gait speed, there is insufficient evidence for possible functional determinants of gait speed in HFrEF. Knowing the possible determinants of gait speed in patients with $\mathrm{HFrEF}$ will be useful in establishing appropriate rehabilitation programs to prevent functional decline and improve the independence level. Therefore, the objective of this study was to investigate the functional determinants of gait speed in patients with HFrEF.

\section{Methods}

This cross-sectional study was carried out at the Physical Therapy and Rehabilitation Department of Dokuz Eylül University. The patients with HFrEF were recruited from the outpatient clinic in the Cardiology Department of Dokuz Eylül University Hospital. In the study, individuals diagnosed with HFrEF according to the 2016 European Society of Cardiology (ESC) Guideline of Heart Failure, and individuals who were functional class I, II, and III of the New York Heart Association (NYHA) were included. Individuals with serious lung disease, arrhythmias, severe valvular heart disease, or anemia were excluded from the study. In addition, individuals with cognitive disorders; orthopedic problems that prevent walking; and neurological diseases such as stroke, parkinson, and multiple sclerosis were also excluded.

The study was performed according to the guidelines of the Declaration of Helsinki. The study protocol was approved by the Ethics Committee of Dokuz Eylül University (file number: 4722GOA; decision number: 2019/12-38; date: 08.05.2019). Written informed consent was obtained from all the participants included in the study.

The etiologies, left ventricular EF, and functional classes of the participants were obtained from the clinical records. Comorbidities of individuals were questioned with Charlson Comorbidities Index (CCI) (13). Dyspnea perception of the participants was evaluated with a modified medical research council (mMRC) scale. The mMRC is a 5-item scale that evaluates dyspnea during daily activities, where zero indicated "no dys- pnea when moving at low speeds or a slight uphill, except for intense exercise," and four indicates "dyspnea when wearing or removing clothes at home" (14). The gait speed was determined with a 4-meter walking test (4MWT). The 4MWT consisted of the participants starting to walk on command $2 \mathrm{~m}$ behind the starting line, starting the stopwatch the moment they cross the starting line and stopping the stopwatch the moment they cross the ending line. The participants were asked to walk at normal speed and maximum speed, and the gait speed was calculated by dividing the walking distance by the time recorded by the stopwatch (15). Functional capacity was evaluated with $6 \mathrm{MWT}$, which was administered according to the American Thoracic Society guidelines. The participants were asked to walk as fast as possible for six minutes in the $30 \mathrm{~m}$ corridor. During the test, the standard expression "you are doing very well" was used to encourage the patient every minute, and the 6 -minute walking distance was recorded at the end of the test (16). The five times sit-to-stand (5-STS) test is an outcome measure used to determine mobility, functional lower limb/extremity strength, and balance capacity. The test was performed with the participants' hips and knees flexed at $90^{\circ}$ and feet in contact with the ground, sitting in a chair without arm support. The participants were asked to get up and sit 5 times as quickly as possible and the time to complete the test was recorded (17). Berg Balance Scale (BBS) was used for clinical evaluation of balance. BBS is a 14-item scale that evaluates the functional balance and includes certain daily activities such as standing out of the chair, standing independently, stepping on the stairs, and standing on one leg. Each item of the scale gets a score between 0 and 4 . The highest score of the scale is 56 , which indicated good balance (18). To evaluate the physical activity of the participants, International Physical Activity Questionnaire ShortForm (IPAQ-SF) was used. IPAQ-SF includes seven items that examine four activity levels, including vigorous intensity activity, moderate intensity activity, walking, and sitting for the past seven days (19). Mini-Mental State Examination (MMSE) was created as a short-term cognitive assessment tool. MMSE consists of 11 items collected under five main headings (orientation, record memory, attention, calculation, and language). The highest score is 30 points, and the ideal threshold in the diagnosis of mild dementia was determined as 24 points (20).

Previous studies have found that the 6MWT distance was an independent determinant of usual gait speed in patients with COPD $\left(R^{2}=0.60, p<0.001\right)$ (21). The sample size for multiple linear analysis, according to the results of that study, was estimated as 59 participants for seven predictors in the model, expected effect size of 0.4 the probability of type I error of 0.05 , statistical power of 0.95 , using $G *$ Power software (version 3.1.9.2, Düsseldorf, Germany).

\section{Statistical analysis}

All data were analyzed using the Statistical Package for Social Sciences statistical software package (version 23.0, IBM Corp., Armonk, NY, USA). Skewness-Kurtosis tests and histograms were used to check normality of distribution. Continuous 
variables were presented as mean \pm standard deviation, whereas categorical variables were presented as number and percent. Pearson product moment correlation coefficients were used to assess the correlations between usual gait speed and following variables: age, body mass index, EF, NYHA, mMRC, 6MWT distance, IPAQ, IPAQ-sitting time, 5STS, BBS, and MMSE. Stepwise multiple linear analysis was used to identify the independent variables that had the most influence on gait speed. Significantly correlated variables (age, NYHA, 6MWT distance, IPAQ, IPAQsitting time, 5STS, BBS) with usual gait speed were included in the regression model. NYHA and mMRC were collinear; therefore, only NYHA was used for modeling to avoid multicollinearity. In addition, receiver operating characteristic (ROC) curve analysis was used to determine whether usual gait speed had discriminative value for poor exercise capacity (6MWT $<300 \mathrm{~m}$ ). The cut-off value of gait speed corresponding to optimal sensitivity and specificity was identified as the point on the ROC curve closest to the $(0,1)$ point (22). Statistical significance was considered as $p<0.05$.

\section{Results}

Fifty-nine patients with HFrEF who met the inclusion criteria were included in the study. The demographic and characteristic features in patients with HFrEF are summarized in Table 1. The etiologies of HF were ischemic heart disease $(74.6 \%)$, hypertensive heart disease $(10.2 \%)$, and non-ischemic dilated cardiomyopathy $(15.2 \%)$.

Correlations between usual gait speed and other parameters in patients with $\mathrm{HFrEF}$ are presented in Table 2. Usual gait speed was negatively correlated with age $(r=-0.368, p=0.004)$, NYHA $(\mathrm{r}=-0.438, p=0.001)$, mMRC score $(\mathrm{r}=-0.422, p=0.001)$, 5STS $(\mathrm{r}=-$ $0.506, p<0.001)$, and IPAQ-sitting time $(r=-0.327, p=0.011)$. Usual gait speed was positively correlated with 6MWT $(r=0.650$, $p<0.001)$, BBS ( $r=0.586, p<0.001)$, and IPAQ $(r=0.305, p=0.019)$.

Stepwise multiple linear regression model of the usual gait speed in patients with HFrEF is presented in Table 3. The 6MWT distance and BBS were independent functional determinants of the usual gait speed in patients with HFrEF, accounting for $44.4 \%$ of the variance. The regression model was confirmed as convenient as $\mathrm{F}$ value was significant $(\mathrm{F}=24.136, p<0.001)$, the variance inflation factors (VIF) were less than 10, the Durbin Watson test value was close to 2 , and residual distribution was random. The regression equation formula is $[-0.912+(0.001 \times 6 \mathrm{MWT}$ distance $\{m\})+(0.024 \times$ BBS \{unit change\})] in patients with HFrEF.

When the model was repeated excluding parameters that may establish a cause-effect relationship with gait speed (6MWT, 5-STS, BBS, and NYHA), the independent determinants of gait speed were age and mMRC score in patients with HFrEF, accounting for $23.2 \%$ of the variance (Table 4). The regression equation is $[1.763+(-0.008 \times$ age $\{y\})+(-0.106 \times$ mMRC score $)]$ in patients with $\mathrm{HFrEF}$.

ROC curve analysis results are presented in Figure 1. Usual gait speed had discriminative value for poor exercise capacity

\begin{tabular}{|lc|}
\hline \multicolumn{2}{|l|}{ Table 1. Demographic and characteristic features in HFrEF } \\
\hline Characteristic & Value \\
\hline Age, years & $65.2 \pm 10.8$ \\
Sex, male & 47 (79.7) \\
BMI, kg/m² & $28.5 \pm 3.9$ \\
EF, \% & $31.1 \pm 7.1$ \\
NYHA class & \\
I & $12(20.3)$ \\
II & $29(49.2)$ \\
III & $18(30.5)$ \\
CCI & $2.5 \pm 0.9$ \\
mMRC score, 0-4 & $2.6 \pm 1.1$ \\
Usual 4-m gait speed (m/s) & $0.93 \pm 0.3$ \\
Maximal 4-m gait speed (m/s) & $1.3 \pm 0.3$ \\
6MWT distance, m & $415.3 \pm 101.6$ \\
IPAO, MET/h/week & $668.6 \pm 763.1$ \\
IPAQ-Sitting, minutes/day & $574.5 \pm 228.1$ \\
5-STS, s & $12.9 \pm 3.3$ \\
BBS & $52.8 \pm 3.6$ \\
MMSE & $27.6 \pm 2.28$ \\
\hline Data were expressed as mean \pm SD or number (percentage). \\
BBS - Berg Balance Scale; BMI - body mass index; CCI - Charlson Comorbidities \\
Index; EF - ejection fraction; HFrEF - heart failure with reduced ejection fraction; IPA0 \\
- International Physical Activity Questionnaire; mMRC - modified medical research \\
council scale; MMSE - mini mental state examination; NYHA - New York heart \\
association; 5-STS - five times sit to stand test; 6MWT - 6 minute walk test \\
\hline
\end{tabular}

Table 2. Correlations between usual gait speed and other parameters

\begin{tabular}{|lcc|}
\hline & $\mathbf{r}$ & $\boldsymbol{P}$-value \\
\hline Age, years & -0.368 & $0.004^{*}$ \\
BMI & -0.114 & 0.390 \\
EF & 0.179 & 0.176 \\
NYHA & -0.438 & $0.001^{*}$ \\
mMRC score & -0.422 & $0.001^{*}$ \\
6MWT distance, m & $0.001^{*}$ & $<0.001^{*}$ \\
IPAO, MET/h/week & 0.305 & $0.019^{*}$ \\
IPAO-Sitting, minutes/day & -0.327 & $0.011^{*}$ \\
5-STS, S & -0.506 & $<0.001^{*}$ \\
BBS & 0.586 & $<0.001^{*}$ \\
MMSE & 0.123 & 0.355 \\
\hline *Statistically significant difference $(P<0.05)$ & \\
BBS - Berg Balance Scale; BMI - body mass index; EF - ejection fraction; IPAO - \\
International Physical Activity Questionnaire; mMRC - modified medical research \\
council scale; MMSE - mini mental state examination; NYHA - New York heart \\
association; 5-STS - five times sit to stand test; 6MWT - 6 minute walk test
\end{tabular}

(6MWT distance $<300 \mathrm{~m}$ ), with an AUC of $0.937(p<0.001,95 \%$ confidence interval 0.86-1.0). Usual gait speed of $0.7 \mathrm{~m} / \mathrm{s}$ had a sensitivity of $88 \%$ and specificity of $70 \%$ for the prediction of poor exercise capacity in patients with $\mathrm{HFrEF}$. 


\begin{tabular}{|c|c|c|c|c|c|c|}
\hline Variable & $\beta$ & SE & Beta & VIF & $t$ & $P$-value \\
\hline Constant & -0.912 & 0.511 & - & - & -1.784 & 0.08 \\
\hline $\begin{array}{l}\text { 6MWT } \\
\text { distance, m }\end{array}$ & 0.001 & 0.000 & 0.468 & 1.829 & 3.535 & $0.001^{*}$ \\
\hline BBS & 0.024 & 0.012 & 0.271 & 1.829 & 2.044 & $0.046^{*}$ \\
\hline \multicolumn{7}{|c|}{$\begin{array}{l}\text { *Statistically significant difference }(P<0.05) \\
\mathrm{R}=0.680, \mathrm{R}^{2}=0.463 \text {, adjusted } \mathrm{R}^{2}=0.444(\mathrm{~F}=24.136, P<0.001) \\
\beta \text { - unstandardized regression coefficient; } \mathrm{SE} \text { - standard error; VIF - variance } \\
\text { inflation factors; } 6 \mathrm{MWT} \text { - } 6 \text { minute walk test; } \mathrm{BBS} \text { - Berg Balance Scale }\end{array}$} \\
\hline
\end{tabular}

Table 4. Stepwise multiple linear regression model of the usual gait speed excluding functional parameters in HFrEF

\begin{tabular}{lcccccc|}
\hline Variable & $\boldsymbol{\beta}$ & SE & Beta & VIF & t & $\boldsymbol{P}$-value \\
\hline Constant & 1.763 & 0.224 & - & - & 7.853 & $<0.001^{*}$ \\
Age, y & -0.008 & 0.003 & -0.291 & 1.048 & -2.469 & $0.017^{*}$ \\
mMRC score, & -0.106 & 0.035 & -0.360 & 1.048 & -3.052 & $0.003^{*}$ \\
$(0-4)$ & & & & & & \\
\hline
\end{tabular}

${ }^{*}$ Statistically significant difference $(P<0.05)$

$\mathrm{R}=0.509, \mathrm{R}^{2}=0.259$, adjusted $\mathrm{R}^{2}=0.232(\mathrm{~F}=9.776, P<0.001)$

$\beta$ - unstandardized regression coefficient; SE - standard error; mMRC - modified

medical research council scale; VIF - variance inflation factors

\section{Discussion}

The main finding of this study indicates that 6MWT distance and balance are functional determinants of usual gait speed in patients with HFrEF, accounting for $44.4 \%$ of the variance. When functional parameters that may establish a cause-effect relationship with gait speed were removed, age and perception of dyspnea were found to be independent determinants of usual gait speed. This study also demonstrates that usual gait speed is correlated with age, NYHA functional class, perception of dyspnea, functional mobility, and physical activity. Furthermore, we demonstrated that the usual gait speed of $0.7 \mathrm{~m} / \mathrm{s}$ was a threshold to predict poor exercise capacity in patients with HFrEF.

The 4MWT, where gait speed is obtained, is a well-known assessment of multi-system wellbeing in older adults and COPD. It is a reliable, easy-to-understand, fast-performing, and inexpensive tool. This test can be performed by nonprofessional staff and in any clinical setting (15). Moreover, 4-m distance allows patients to achieve a constant walking speed without revealing cardiorespiratory symptoms (23).

The 6MWT is a valid, reliable, and well-tolerated test evaluating functional capacity in patients with HF. The distance walked over 6 minutes provides prognostic value that is similar to peak V02 and VE/VCO2 slopes which are obtained from the cardiopulmonary exercise test in patients with HF (24). In addition to functional capacity, gait speed is another independent predictor of prognosis in both $\mathrm{HF}$ and other disease populations $(6,7)$. Karpman et al. (21) found the 6MWT distance one of the strongest determinants of gait speed in COPD. In accordance with previous studies, 6MWT distance was found to be one of the determinants

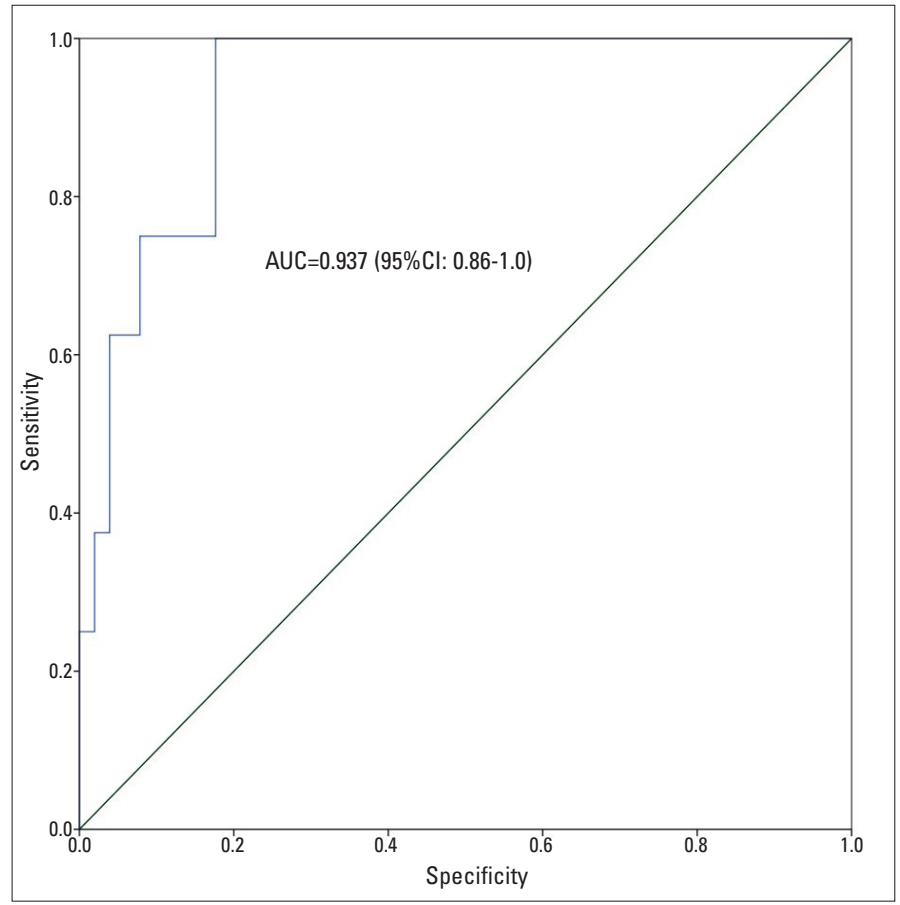

Figure 1. Receiver operating characteristic curve for predicting poor exercise capacity calculated by using usual gait speed AUC - area under the curve; $\mathrm{Cl}$ - confidence interval

of gait speed in our study. Therefore, we think that functional capacity contributes to gait speed in patients with HFrEF.

It is known that gait speed and balance control are related during walking in healthy elderly people (25). A previous study has suggested that the balance control evaluated with unilateral stance is impaired in HF (26). In addition, in our study, the mean BBS score of patients with HF was found to be lower than the elderly of similar ages living in the community (27). Therefore, patients with HF may experience ambulatory difficulty owing to both effort intolerance arising from cardiac dysfunction and impaired balance control during walking. On the basis of all of these, in our study where we investigated the relationship between gait speed and functional balance, we found balance as one of the determinants of gait speed.

Older patients with HFrEF are at risk for adverse functional outcomes because of their mobility performance (26). According to our results, functional mobility is associated with gait speed. This finding confirms the relation between adverse functional outcomes and mobility in patients with HFrEF.

Physical activity is important in HF to improve prognosis, functional capacity, and quality of life (28). Physical inactivity is associated with higher all-cause and cardiac mortality in symptomatic HF (29). The relationship between physical activity and usual gait speed has not been investigated in the HF population. We found that physical activity and sedentary time are associated with usual gait speed, but physical activity and sedentary time do not independently inform concerning gait speed according to multivariate regression analysis. This result may be because IPA $Q$ underestimates the sedentary time and overestimates moderate-to-vigorous physical activity in HF (30). 
Pulignano et al. (7) demonstrated that low gait speed is independently associated with age, cognition, and LVEF in patients over 70 years of age with HF across a wide range of EF. In our study, contrary to previous studies, age, cognition, and LVEF were not independently associated with gait speed. These results may be owing to the fact that Pulignano et al. (7) classified their patients in three groups according to gait speed, whereas our study assessed all the patients as one group. In addition, our patients had a smaller mean age and only reduced EF.

Usual gait speed was highly discriminative to determine poor exercise capacity in our study similar to previous studies $(6,21)$. Karpman et al. (21) have found that the gait speed of $0.8 \mathrm{~m} / \mathrm{s}$ is a cut-off for the prediction of poor exercise capacity in patients with COPD. In another study, Kamiya et al. (6) have reported that a gait speed of $<0.9 \mathrm{~m} / \mathrm{s}$ is a threshold for poor exercise capacity in patients with CVD, with sensitivity and specificity values above $80 \%$. According to our results, a gait speed of $0.7 \mathrm{~m} / \mathrm{s}$ is an indicator of poor exercise capacity in patients with HFrEF, with a sensitivity of $88 \%$ and specificity of $70 \%$. This finding is not surprising considering Kamiya et al. (6) included patients with different cardiac diseases, including acute heart failure, cardiac surgery, acute coronary syndrome, and other clinical entities and performed their evaluation at hospital discharge. However, our study recruited only clinically stable patients with HFrEF from an outpatient clinic. Therefore, gait speed has great clinical importance, and the clinical status of the patients should be considered when interpreting it.

This study looked at the relationship between gait speed and functional outcomes, including NYHA, 6MWT distance, mobility, balance, and physical activity in patients with HF. The findings of this study may have substantial clinical implications. The 6MWT distance and balance, which are the determinants of gait speed, are modifiable. Therefore, these determinants should be taken into consideration when planning cardiac rehabilitation programs for patients with HFrEF.

\section{Study limitations}

This study had some limitations, including the fact that our patients had NYHA I, II, and III functional classes and reduced LVEF; therefore, the generalizability of our findings to all HF populations is limited. Second, we considered the usual gait speed rather than fast gait speed because usual gait speed has an advantage in prognosis estimation.

\section{Conclusion}

To the best of our knowledge, this is the first study investigating the possible functional determinants of the gait speed in patients with HFrEF. Our study indicates that functional capacity and balance are independent functional determinants of gait speed in HFrEF. Gait speed is discriminative to determine poor exercise capacity in patients with HFrEF.

Conflict of interest: None declared.

\section{Peer-review: Externally peer-reviewed.}

Author contributions: Concept - A.T., B.Ö.K., S.A., I.Ö., E.Ö., B.Ş., B.A., S.S.; Design - A.T., B.Ö.K., S.A., I.Ö., E.Ö., B.Ş., B.A., S.S.; Supervision - S.S.; Fundings - None; Materials - E.Ö., B.Ş., B.A.; Data collection \&/ or processing - A.T., B.Ö.K., S.A., I.Ö.; Analysis \&/or interpretation - A.T., B.Ö.K., I.Ö., S.S.; Literature search - A.T., B.Ö.K., S.A., I.Ö., E.Ö., B.Ş., B.A., S.S.; Writing - A.T., S.S.; Critical review - A.T., B.Ö.K., S.A., I.Ö., E.Ö., B.Ş., B.A., S.S.

\section{References}

1. Savarese G, Lund LH. Global Public Health Burden of Heart Failure. Card Fail Rev 2017; 3: 7-11. [Crossref]

2. Haykowsky MJ, Tomczak CR, Scott JM, Paterson DI, Kitzman DW. Determinants of exercise intolerance in patients with heart failure and reduced or preserved ejection fraction. J Appl Physiol (1985) 2015; 119: 739-44. [Crossref]

3. Piña IL, Apstein CS, Balady GJ, Belardinelli R, Chaitman BR, Duscha BD, et al.; American Heart Association Committee on exercise, rehabilitation, and prevention. Exercise and heart failure: $A$ statement from the American Heart Association Committee on exercise, rehabilitation, and prevention. Circulation 2003; 107: 1210 25. [Crossref]

4. Rostagno C, Olivo G, Comeglio M, Boddi V, Banchelli M, Galanti G, et al. Prognostic value of 6 -minute walk corridor test in patients with mild to moderate heart failure: comparison with other methods of functional evaluation. Eur J Heart Fail 2003; 5: 247-52. [Crossref]

5. Fritz S, Lusardi M. White paper: "walking speed: the sixth vital sign". J Geriatr Phys Ther 2009; 32: 46-9. [Crossref]

6. Kamiya K, Hamazaki N, Matsue Y, Mezzani A, Corrà U, Matsuzawa $\mathrm{R}$, et al. Gait speed has comparable prognostic capability to sixminute walk distance in older patients with cardiovascular disease. Eur J Prev Cardiol 2018; 25: 212-9. [Crossref]

7. Pulignano G, Del Sindaco D, Di Lenarda A, Alunni G, Senni M, Tarantini $L$, et al.; IMAGE-HF Study Investigators. Incremental Value of Gait Speed in Predicting Prognosis of Older Adults With Heart Failure: Insights From the IMAGE-HF Study. JACC Heart Fail 2016; 4: 289-98. [Crossref]

8. Tanaka S, Kamiya K, Hamazaki N, Matsuzawa R, Nozaki K, Nakamura T, et al. Short-Term Change in Gait Speed and Clinical Outcomes in Older Patients With Acute Heart Failure. Circ J 2019; 83: 1860-7. [Crossref]

9. McDermott MM, Tian L, Liu K, Guralnik JM, Ferrucci L, Tan J, et al. Prognostic value of functional performance for mortality in patients with peripheral artery disease. J Am Coll Cardiol 2008; 51: 1482-9. [Crossref]

10. Cooper R, Kuh D, Hardy R; Mortality Review Group; FALCon and HALCyon Study Teams. Objectively measured physical capability levels and mortality: systematic review and meta-analysis. BMJ 2010; 341: c4467. [Crossref]

11. Idland G, Engedal K, Bergland A. Physical performance and 13.5year mortality in elderly women. Scand J Public Health 2013; 41: 102-8. [Crossref]

12. Pepera GK, Sandercock GR, Sloan R, Cleland JJ, Ingle L, Clark AL. Influence of step length on 6-minute walk test performance in patients with chronic heart failure. Physiotherapy 2012; 98: 325-9. [Crossref] 
13. Roffman C, Buchanan J, Allison G. Charlson comorbidities index. J Physiother 2016; 62: 171. [Crossref]

14. Fletcher CM, Clifton M, Fairbairn AS, Fry J, Gilson JC, Higgins ITT, et al. Standardised questionnaire on respiratory symptoms. A statement prepared and approved by the MRC Committee on the Aetiology of Chronic Bronchitis (MRC breathlessness score). $\mathrm{Br}$ Med J 1960; 2: 1665.

15. Kon SS, Patel MS, Canavan JL, Clark AL, Jones SE, Nolan CM, et al. Reliability and validity of 4-metre gait speed in COPD. Eur Respir J 2013; 42: 333-40. [Crossref]

16. ATS Committee on Proficiency Standards for Clinical Pulmonary Function Laboratories. ATS statement: guidelines for the six-minute walk test. Am J Respir Crit Care Med 2002; 166: 111-7. [Crossref]

17. Mong Y, Teo TW, Ng SS. 5-repetition sit-to-stand test in subjects with chronic stroke: reliability and validity. Arch Phys Med Rehabil 2010; 91: 407-13. [Crossref]

18. Berg K, Wood-Dauphine S, Williams J, Gayton D. Measuring balance in the elderly: preliminary development of an instrument. Physiotherapy Canada 1989; 41: 304-11. [Crossref]

19. Lee PH, Macfarlane DJ, Lam TH, Stewart SM. Validity of the International Physical Activity Questionnaire Short Form (IPAQ-SF): a systematic review. Int J Behav Nutr Phys Act 2011; 8: 115. [Crossref]

20. Mitchell AJ. The Mini-Mental State Examination (MMSE): update on its diagnostic accuracy and clinical utility for cognitive disorders. Cognitive screening instruments. Springer; 2017. p.37-48. [Crossref]

21. Karpman C, DePew ZS, LeBrasseur NK, Novotny PJ, Benzo RP. Determinants of gait speed in COPD. Chest 2014; 146: 104-10. [Crossref]

22. Akobeng AK. Understanding diagnostic tests 3: Receiver operating characteristic curves. Acta Paediatr 2007; 96: 644-7. [Crossref]
23. Morlino P, Balbi B, Guglielmetti S, Giardini M, Grasso M, Giordano $C$, et al. Gait abnormalities of COPD are not directly related to respiratory function. Gait Posture 2017; 58: 352-7. [Crossref]

24. Giannitsi S, Bougiakli M, Bechlioulis A, Kotsia A, Michalis LK, Naka KK. 6-minute walking test: a useful tool in the management of heart failure patients. Ther Adv Cardiovasc Dis 2019; 13: 1753944719870084. [Crossref]

25. Helbostad JL, Moe-Nilssen R. The effect of gait speed on lateral balance control during walking in healthy elderly. Gait Posture 2003; 18: 27-36. [Crossref]

26. Hummel SL, Herald J, Alpert C, Gretebeck KA, Champoux WS, Dengel DR, et al. Submaximal oxygen uptake kinetics, functional mobility, and physical activity in older adults with heart failure and reduced ejection fraction. J Geriatr Cardiol 2016; 13: 450-7.

27. Steffen TM, Hacker TA, Mollinger L. Age-and gender-related test performance in community-dwelling elderly people: Six-Minute Walk Test, Berg Balance Scale, Timed Up \& Go Test, and gait speeds. Phys Ther 2002; 82: 128-37. [Crossref]

28. Zores F, lliou MC, Gellen B, Kubas S, Berthelot E, Guillo $P$, et al. Physical activity for patients with heart failure: Position paper from the heart failure (GICC) and cardiac rehabilitation (GERS-P) Working Groups of the French Society of Cardiology. Arch Cardiovasc Dis 2019; 112: 723-31. [Crossref]

29. Doukky R, Mangla A, Ibrahim Z, Poulin MF, Avery E, Collado FM, et al. Impact of Physical Inactivity on Mortality in Patients With Heart Failure. Am J Cardiol 2016; 117: 1135-43. [Crossref]

30. Schmidt C, Santos M, Bohn L, Delgado BM, Moreira-Gonçalves D, Leite-Moreira $A$, et al. Comparison of questionnaire and accelerometer-based assessments of physical activity in patients with heart failure with preserved ejection fraction: clinical and prognostic implications. Scand Cardiovasc J 2020; 54: 77-83. [Crossref] 